\title{
SEISMIC BEHAVIOR OF STEEL MONORAIL BRIDGES UNDER TRAIN LOAD DURING STRONG EARTHQUAKES
}

\section{$\operatorname{AUTHOR}(S)$ :}

KIM, C. W.; KAWATANI, M.; KANBARA, T.; NISHIMURA, N.

\section{CITATION:}

KIM, C. W....[et al]. SEISMIC BEHAVIOR OF STEEL MONORAIL BRIDGES UNDER TRAIN LOAD DURING STRONG EARTHQUAKES. Journal of Earthquake and Tsunami 2013, 07(02): 1350006.

\section{ISSUE DATE:}

2013-06

URL:

http://hdl.handle.net/2433/178731

\section{RIGHT:}

(C) World Scientific Publishing Company; この論文は出版社版でありま せん。引用の際には出版社版をご確認ご利用ください。; This is not the published version. Please cite only the published version. 


\title{
SEISMIC BEHAVIOR OF STEEL MONORAIL BRIDGES UNDER TRAIN LOAD DURING STRONG EARTHQUAKES
}

\author{
C.W. KIM \\ Department of Civil and Earth Resources Engineering, Kyoto University \\ Kyotodaigaku Katsura, Nishikyo-ku, Kyoto 615-8540, Japan \\ M. KAWATANI \\ Department of Civil Engineering, Kobe University \\ 1-1 Rokkodai, Nada-ku, Kobe 657-8501, Japan \\ T. KANBARA \\ Yokogawa Bridge Corp. \\ 27 Yamano-cho, Funabashi, Chiba 273-0026, Japan \\ N. NISHIMURA \\ Department of Civil Engineering, Osaka University \\ 1-1 Yamadaoka, Suita, Osaka 565-0871, Japan
}

Accepted 25 March, 2013

\begin{abstract}
This paper investigated dynamic responses of steel monorail bridges incorporating train-bridge interaction under strong earthquakes. Two types of steel monorail bridges were considered in the study: a conventional type with steel track-girder; an advanced type with composite track-girder and simplified lateral bracing system. During strong earthquakes, monorail train was assumed standing on the track-girder of monorail bridges. Observations through the analytical study showed that considering the monorail train as additional mass rather than a dynamic system in numerical modeling overestimated effect of the train load on seismic performance of monorail bridges. Earlier plastic deformations at the end bracing of the girder system absorbed seismic energy and reduced the stress at the pier base.
\end{abstract}

Keywords: Elasto-plastic response; monorail bridge; seismic behavior; simplified structure; steel bridge; train load.

\section{Introduction}

Good seismic performance of bridge structures has been an issue of great concern in the countries located in earthquake-prone regions. Economic design of civil infrastructures also has been another important consideration. To satisfy both safety and economic requirements in seismic design, it needs better understanding about the mechanism of structural systems under earthquakes. Satisfying both safety and economic requirements also has been a keen technical issue even in design of monorail bridges.

In seismic design of monorail bridges the effect of the train load is considered as additional mass differently from highway bridges because of a relatively large portion of train's weight to the total weight of the entire bridge. However, it is obviously improper to treat the train on the monorail bridge just as an additional mass in seismic design, since the train on 
monorail bridges is a dynamic system as shown in Fig. 1 rather than additional mass, and the monorail train of the straddle-type acts as a sprung mass on the track-girder during earthquakes [Kim and Kawatani, 2006; Kim et al., 2007].

Cost-efficiency in modern bridge design has been a driving force of rationalized design strategies even for monorail bridges. A new type of steel-concrete composite bridge for monorails (hereafter, advanced bridge) has been developed. A simplified lateral bracing system in the advanced bridge constitutes the major difference from conventional bridges. The composite steel girder with an RC track-girder is adopted to enhance braking performance of monorail trains, even though it makes the advanced bridge heavier than the conventional bridge. Lee et al. [2006] showed that the advanced bridge is more easily affected by lateral loading from monorail train than the conventional bridge. That fact together with the advanced scheme already described suggests comprehensive investigations on the seismic performance of the advanced bridge for the simplified lateral bracing system and the composite track girder might engender problems related to seismic performance of the bridge.

Rather limited efforts have been devoted to the effects of train dynamics on the seismic resistance of bridges, but some interesting studies have explored dynamic stability of railway trains and other vehicles with ground motion. Miyamoto et al. [1997] estimated the running safety of trains under earthquakes on the condition that the train is set as stationary on the track. Yang and $\mathrm{Wu}$ [2002] investigated the dynamic stability of trains moving over bridges that were shaken by an earthquake. Some studies have examined dynamic stability of trains or other vehicles under seismic motions without considering interaction with bridge structures. Maruyama and Yamazaki [2002] performed a seismic response analysis on the stability of running vehicles.

Studies on seismic responses of highway bridges considering live loads have been reported by Japanese researchers. Kameda et al. [1999] investigated the effect of vehicle loading on seismic responses of highway bridges. That study concluded that the seismic response of the bridge can increase or decrease according to the phase difference between the vehicle and bridge systems. Kawatani et al. [2008] analyzed the seismic response of a steel plate girder bridge under vehicle loadings during a moderate earthquake. The observations from the numerical analysis demonstrated that heavy vehicles, acting as dynamic system, can reduce the seismic response of bridges under a ground motion with low frequency characteristics, but the vehicles have the opposite effect and slightly amplify the seismic response of the bridge under high frequency ground motion. A recent study on the effects of live load on a highway bridge under a moderate earthquake in the horizontal and vertical directions is reported by Kim et al. [2011]. The study concluded that the seismic response of the bridge is amplified when the vehicle is considered as merely additional gravity load or mass and the amplification is dependent on the relationship between the fundamental frequency of the bridge and the response spectrum of the ground motion. However when the vehicle is considered as dynamic or mass-spring-damper system, which is more realistic, the dynamic effect of the vehicle is greater than its gravity load effect and thus it reduces the seismic responses. In addition the study also showed that the effect of a moving vehicle as compared to a stationary vehicle is negligible.

Kim and Kawatani [2006] investigated the seismic response of monorail bridges under moderate earthquakes. The study concludes that existing design methods which consider the train as an additional mass provide a conservative result, and also shows that seismic re- 
sponses of the advanced bridge, such as the displacement at the span center and the shear force at the bearing, are greater than those of the conventional bridge because of the heavier girder weight and less lateral bracing of the advanced bridge than those of the conventional bridge. For the seismic responses of high speed railway bridges considering train-bridge interaction, He et al. [2011] numerically investigated the seismic responses of viaducts for high-speed train. They reported a damper effect of train to the seismic response of the viaduct.

A question remaining yet to be answered is what would be the seismic performance of the advanced monorail bridge under strong ground motions. In this study, therefore, seismic responses of the conventional and advanced monorail bridges were examined to clarify the effect of rationalized concept for steel monorail bridges on seismic performance. A dynamic elasto-plastic response analysis for steel monorail bridges was carried out to investigate nonlinear dynamic responses of monorail bridges considering train dynamics under strong earthquake. The monorail train, which was idealized as a model with 4DOFs in transverse direction, was assumed to be standing on the track-girder of the monorail bridge during strong earthquakes.

\section{Numerical Models}

\subsection{Bridges}

The general layout and cross-section of the advanced and conventional bridges are shown in Fig. 2. Elevation and cross-sectional views of the piers are appeared in Fig. 3. The span length of the bridges is $42.8 \mathrm{~m}$, and pier height is $10 \mathrm{~m}$. Properties of bridges are summarized in Tables 1 and 2. The cross-section of piers was designed for the Level-II ground motion which is the strong ground motion specified in the code of Japan Road Association [2002] (hereafter, JRA). On the one hand the advanced bridge which adopts RC track-girder is heavier than the conventional bridge which adopts steel-box track-girders. On the other hand the advanced bridge reduces the number of local members about $70 \%$ comparing to the conventional bridge. The advanced bridge thus is expected to reduce the total construction cost up to $40 \%$ less than that of the conventional bridge.

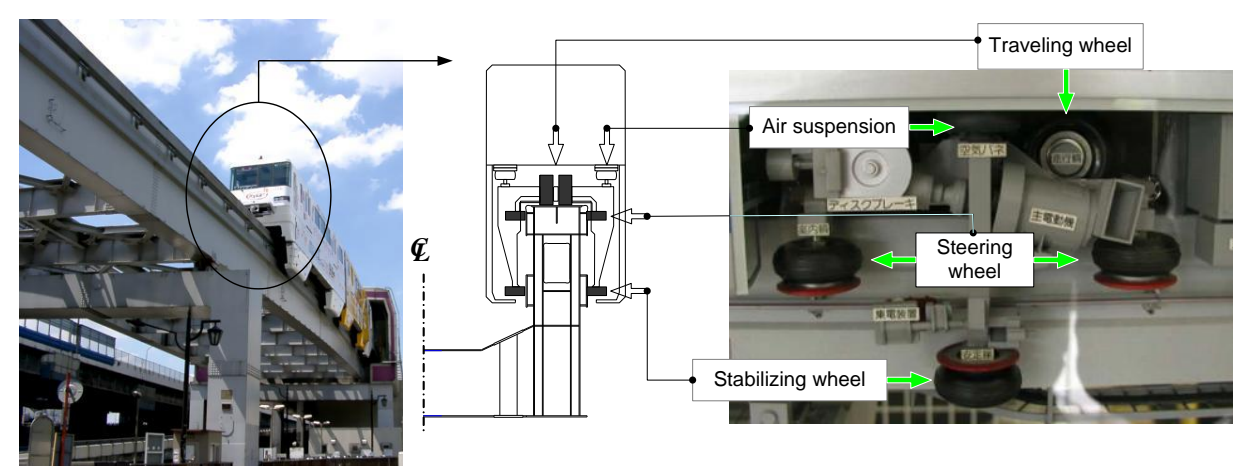

Fig. 1. Straddle-type monorail train. 
Table 1. Properties of monorail bridge superstructure.

\begin{tabular}{|c|c|c|c|c|c|}
\hline Property & $\begin{array}{l}\text { Steel girder } \\
\text { (SM490Y) }\end{array}$ & RC slab & $\begin{array}{l}\text { End crossbeam } \\
\quad(\mathrm{SM} 400)\end{array}$ & $\begin{array}{l}\text { Crossbeam } \\
\text { (SM400) }\end{array}$ & $\begin{array}{l}\text { Lateral bracing } \\
\quad(\mathrm{SM} 400)\end{array}$ \\
\hline Numbers & $2(2)$ & - & $2(2)$ & $7(2)$ & $32(8)$ \\
\hline Young's modulus (GPa) & $205(205)$ & 45 & $205(205)$ & $205(205)$ & $205(205)$ \\
\hline width (mm) & $640(690)$ & 850 & $300(300)$ & $300(320)$ & - \\
\hline flange thickness (mm) & $13(18)$ & 415(depth) & $28(22)$ & $24(19)$ & - \\
\hline depth (mm) & $2385(2782)$ & - & $844(844)$ & $652(681)$ & $176(134)$ \\
\hline thickness (mm) & $11(11)$ & - & $16(11)$ & $13(9)$ & $8(12)$ \\
\hline Lower $\quad$ width $(\mathrm{mm})$ & $640(840)$ & - & $300(300)$ & $300(320)$ & $200(204)$ \\
\hline flange thickness (mm) & $25(19)$ & - & $28(22)$ & $24(19)$ & $12(10)$ \\
\hline $\begin{array}{l}\text { Yield stress (MPa) } \\
\text { Remarks ( ): advanced bridge }\end{array}$ & $353(353)$ & 45 & $235(235)$ & 235 (235) & $235(235)$ \\
\hline
\end{tabular}

Table 2. Properties of monorail bridge substructure.

\begin{tabular}{llll}
\hline Item & Material & Advanced bridge & Conventional bridge \\
\hline Cross-section $(\mathrm{mm})$ & SM490Y & $2000 \times 1800$ & $1800 \times 1600$ \\
Thickness of flange plate $t_{f}(\mathrm{~mm})$ & SM490Y & 24 & 28 \\
Thickness of web plate $t_{w}(\mathrm{~mm})$ & SM490Y & 22 & 24 \\
Area $\left(\mathrm{m}^{2}\right)$ & & 0.2364 & 0.2392 \\
Moment of inertia around weak axis $\left(\mathrm{m}^{4}\right)$ & & 0.122365 & 0.09891 \\
Width-thickness ratio of flange plate $R_{f}$ & & 0.3 & 0.255 \\
Width-thickness ratio of web plate $R_{w}$ & & 0.346 & 0.335 \\
Longitudinal stiffener on flange $(\mathrm{mm})$ & SM490Y & $160 \times 22$ & $200 \times 27$ \\
Longitudinal stiffener on web (mm) & SM490Y & $160 \times 22$ & $160 \times 22$ \\
Number of stiffeners on flange & & 5 & 4 \\
Number of stiffeners on web & & 4 & 3 \\
Width-thickness ratio of longitudinal stiffener on flange $R_{S f}$ & & 0.483 & 0.492 \\
Width-thickness ratio of longitudinal stiffener on flange $R_{S w}$ & & 0.483 & 0.483 \\
\hline
\end{tabular}

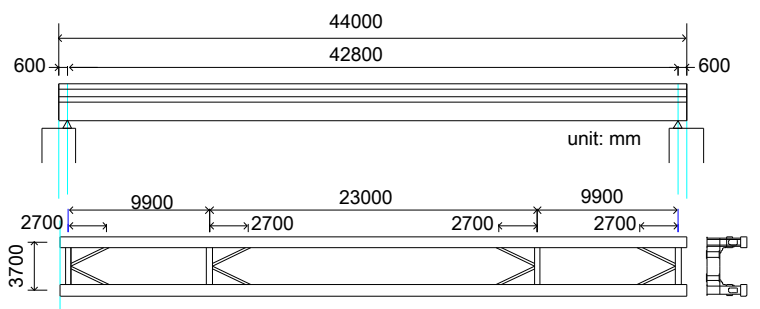

(a)

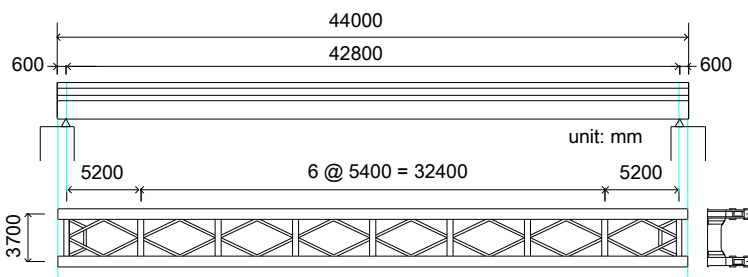

(b)
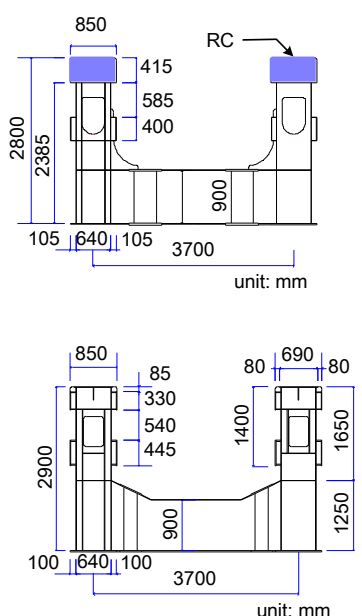

Fig. 2. Layout of steel bridges: (a) advanced bridge; and (b) conventional bridge. 


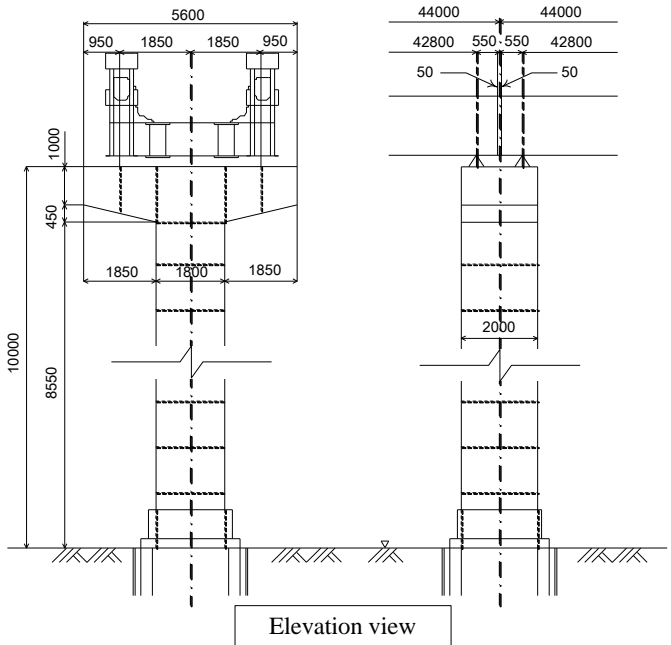

(a)
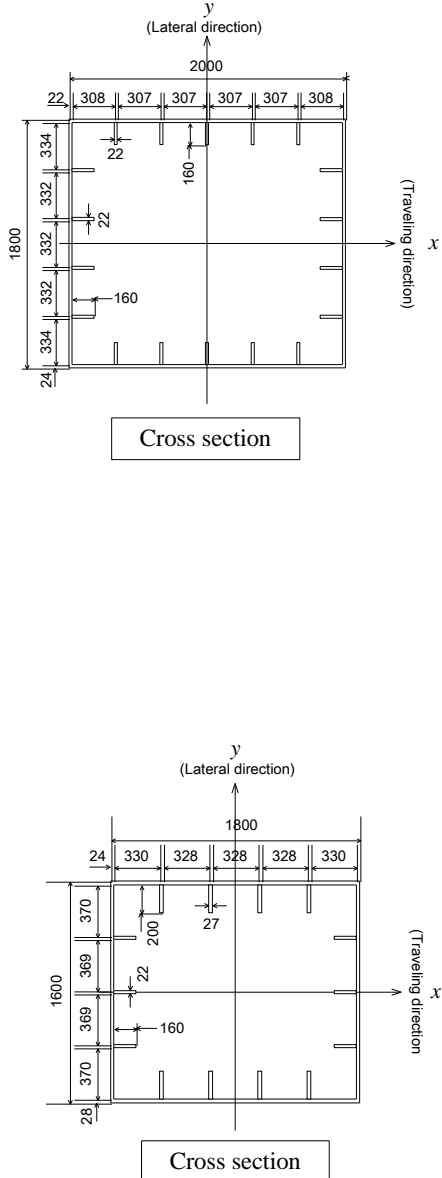

(b)

Fig. 3. Layout of steel piers: (a) advanced type bridge; and (b) conventional type bridge.

The FE models of the bridges are shown in Fig. 4. The FE model of the advanced bridge comprises 275 beam elements and 261 nodes. The conventional bridge model comprises 327 beam elements and 243 nodes. Each member is modeled by the beam element with 6 DOFs at each node. Two different FE models were adopted to consider train load on the seismic response of the monorail bridge: FE models considering train as additional mass of the bridge as shown in Fig. 4(a); and 4DOFs dynamic system as shown in Fig. 4(b). To consider an inertia effect of the adjacent track-girders, a half of the mass of the adjacent girders is lumped on piers of the FE model as shown in Fig. 4. 

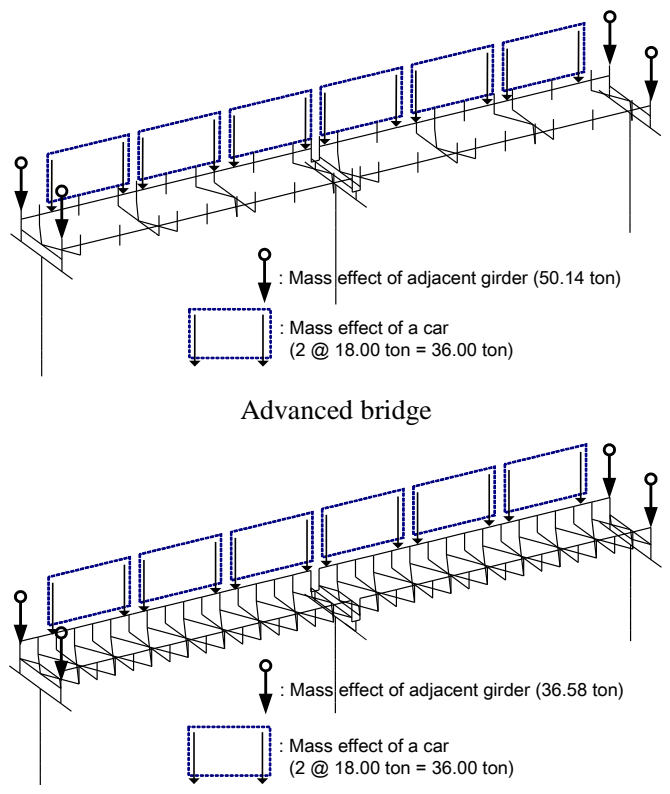

Conventional bridge

(a)

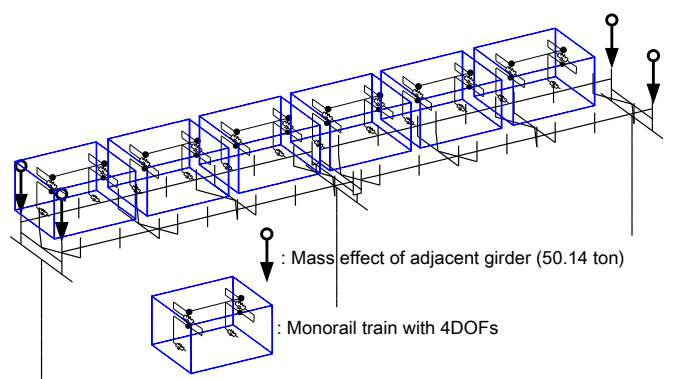

Advanced bridge

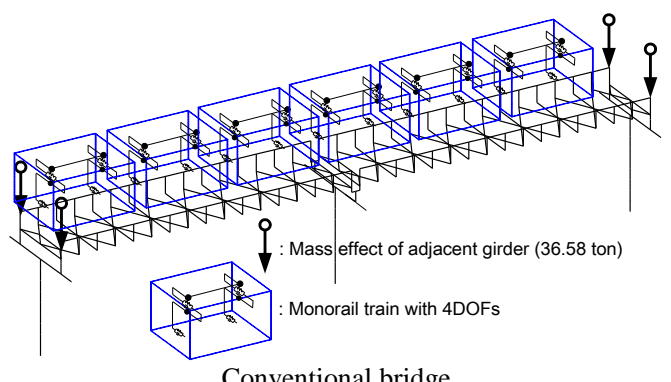

(b)

Fig. 4. FE models of steel bridges: (a) with considering train as additional mass; (b) with considering train's dynamic system. 

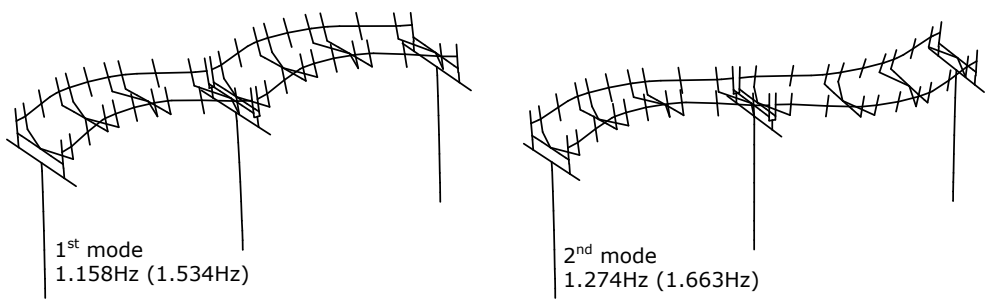

(a)
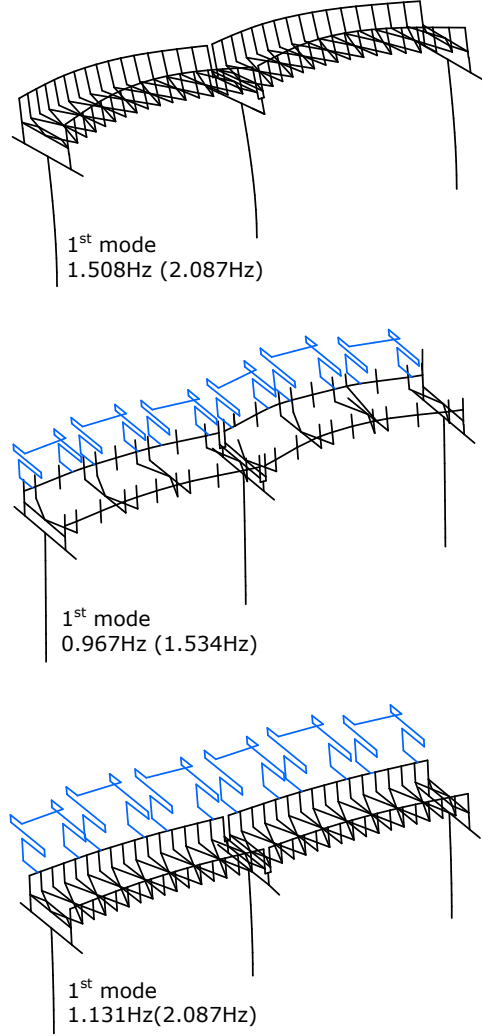

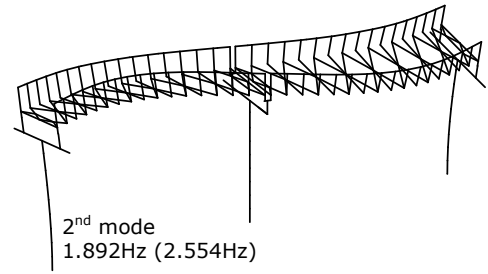

(b)

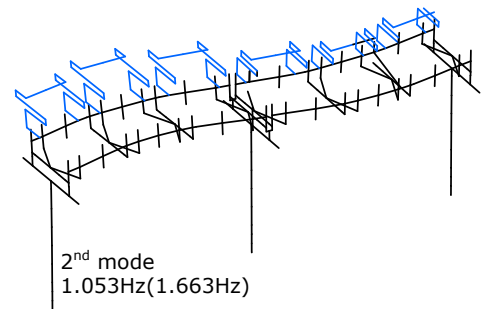

(c)

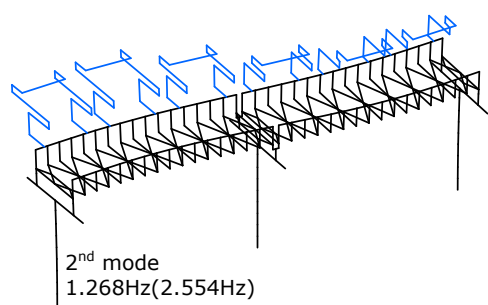

(d)

Fig. 5. Frequencies and mode shapes of the first two modes: (a) advanced bridge considering train as additional mass (in the parenthesis: w/o considering train); (b) conventional bridge considering train as additional mass (in the parenthesis: w/o considering train); (c) advanced bridge considering train's dynamic system (in the parenthesis: w/o considering train); and (d) conventional bridge considering train's dynamic system (in the parenthesis: w/o considering train).

\subsection{Natural Frequencies and Mode Shapes of Bridges}

The eigenvalue analysis was carried out to investigate how the difference of train load model on the bridges influences to the natural frequencies and mode shapes of the monorail bridge. First two fundamental frequencies and relevant mode shapes are summarized in Fig. 
5 in which the frequency in the parenthesis indicates the frequency without considering train. Modeling train on the bridge as additional mass of the bridge led to decrease of natural frequencies as expected. Moreover, the natural frequency considering train as a dynamic system on the bridges showed drastic decrease of the frequency comparing to the FE model considering train as additional mass. In comparing the frequency of two bridges with the same mode shape, the advanced bridge has lower frequency than the conventional bridge, which is caused by heavier track-girders of the advanced bridge than the conventional bridge.

Change of the natural frequency caused by the train load implies importance of the train load in the seismic response analysis of monorail bridges since seismic responses of bridges depend on the response spectrum of ground motions.

\subsection{Monorail Train}

The monorail train comprising six cars in operation was assumed to have weight of 338 $\mathrm{kN} /$ car including passengers. The train was also assumed to be standing on the bridges during strong earthquakes. In order to clarify effects of dynamic system of train on seismic performance of monorail bridges, the train is idealized as a model with 4DOFs in transverse direction as shown in Fig. 6. The natural frequency for sway of the train body was $1.45 \mathrm{~Hz}$, while the frequency for the bogie was $5.29 \mathrm{~Hz}$ from the eigenvalue analysis.

\subsection{Ground Motions}

Strong ground motions used in the seismic response analysis of monorail bridges are the Level-II ground acceleration of moderate soil sites (Group-II) [Japan Road Association, 2002]. Three ground accelerations are used in this study since the JRA code recommends to assess the seismic performance under strong earthquakes by utilizing the average response estimated by considering at least three ground motions.

Fig. 7 shows the ground motions which are modified seismic records obtained from the 1995 Kobe earthquake, in which three ground motions were named as JR-Takatori-StationNS (JRTS-NS), JR-Takatori-Station-EW (JRTS-EW) and Osaka-Gas-Fukiai-EW (OSGFEW). The JRA code also specifies the performance level under strong ground motions depending on the importance of bridges: standard bridges should be free from a critical failure, while important bridges should survive and function without severe damages.

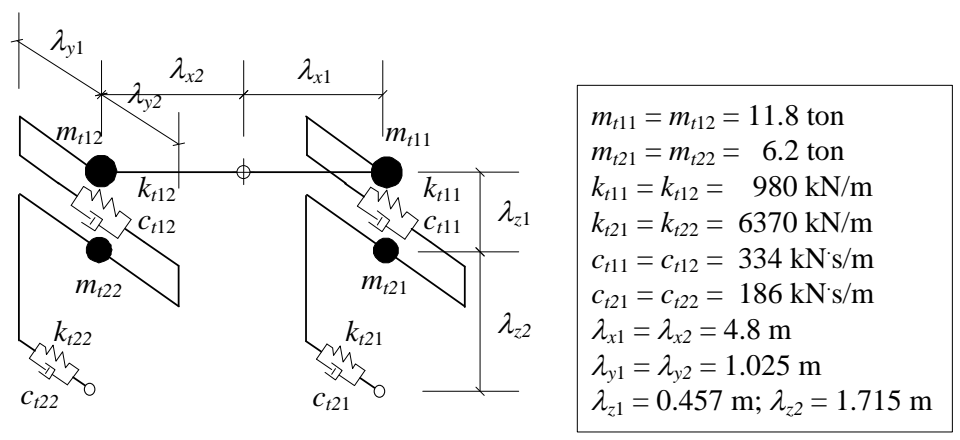

Fig. 6. Train model with 4DOF. 


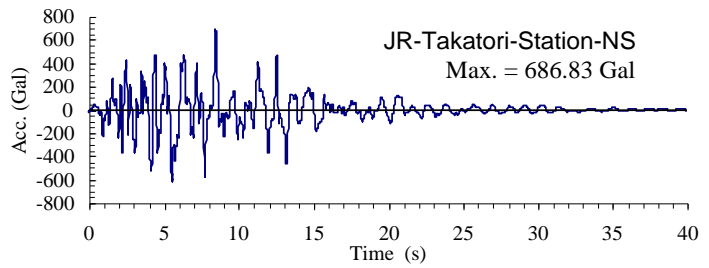

(a)

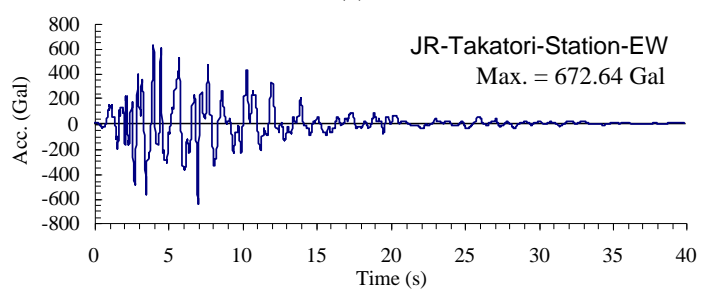

(b)

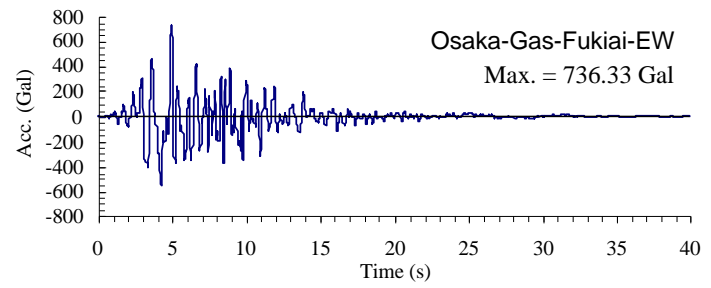

(c)

Fig. 7. Level-II ground motions of moderate soil sites (Group-II): (a) JR-Takatori-Station-NS (JRTS-NS); (b) JRTakatori-Station-EW (JRTS-EW); (c) Osaka-Gas-Fukiai-EW (OSGF-EW).

\section{Seismic Response Analysis}

An existing program code for elasto-plastic finite displacement analysis of steel structures [Ohnomi, 1996] was employed to determine seismic responses of steel monorail bridges under strong earthquakes. The code adopts the Rayleigh damping and the constitutive equation expressing the stress-strain relationship of the element taken from the monotonic loading curve by Nishimura et al. [1995, 1998]. The constitutive equation considered the Bauschinger effect and cyclic strain hardening produced during hysteretic plastic deformation. Newmark's $\beta$ method was adopted to solve simultaneous differential equations of the bridge system under earthquakes. The value of 0.25 was used for $\beta$. The damping constant of the bridges under earthquakes was assumed as $5 \%$. The modified Newton-Raphson iteration technique [Criesfield, 1979] was used as a non-linear iterative solution strategy. Therein the convergence criterion with the tolerance of 1/1000 based on out-of-balance force was used after yielding.

The displacement at the pier top, plastic deformation at the pier base and lateral shear force at a bearing are examined. Fig. 8 shows details of the observation points. 


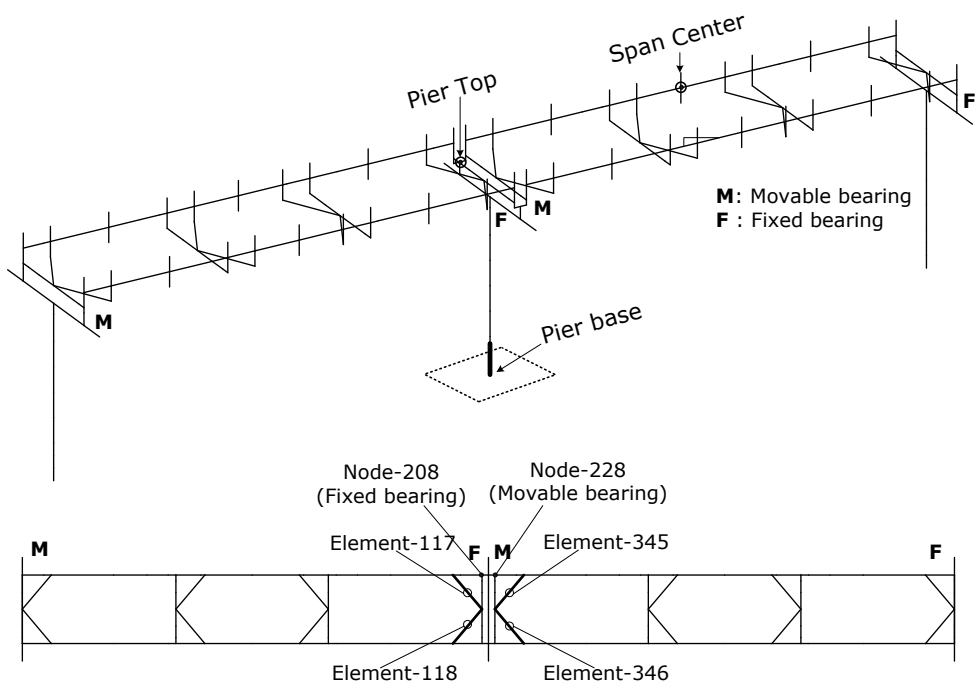

(a)

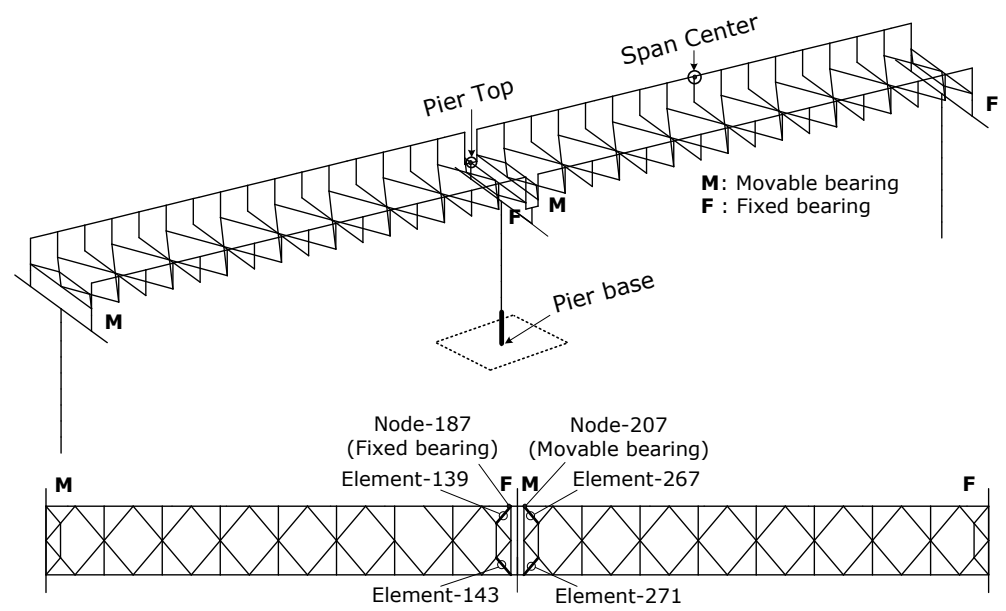

(b)

Fig. 8. Observation points: (a) advanced bridge; and (b) conventional bridge.

\section{Results}

The elasto-plastic finite displacement analysis was carried out and provided displacement responses at the pier top and hysteresis of stress-strain loop at the pier base as well as at the end bracing members of each bridge under strong earthquakes. In order to save space, those responses due to the JRTS-NS ground motion as well as responses of the bridge model without considering train are omitted in this paper for no critical plastic deformations was observed.

Figs. 9 and 10 show dynamic responses of the advanced and conventional bridges subjected to the JRTS-EW ground motion, respectively. It was observed that the largest residu- 
al displacement at the pier top occurred in the advanced bridge by considering train as additional mass. The residual deformation was caused by the plastic deformation of the pier base: the residual displacement was about $17 \mathrm{~cm}$ at the pier top as shown in Fig. 9(a). However, considering train as a dynamic system kept elastic behavior of the pier base of the advanced bridge as shown in Fig. 9(b). For the conventional bridge both pier base and end bracing members demonstrated no clear plastic deformations. It is noteworthy that the stress of the end bracing members of the conventional bridge $\left(f_{\max }=279 \mathrm{kgf} / \mathrm{cm}^{2}\right.$ as shown in Fig. $10(\mathrm{~b}))$ was about 10 times less than that of the advanced bridge $\left(f_{\max }=3600 \mathrm{kgf} / \mathrm{cm}^{2}\right.$ as shown in Fig. 9(b)), which was caused by deploying denser bracing members of the conventional bridge comparing to the advanced bridge.
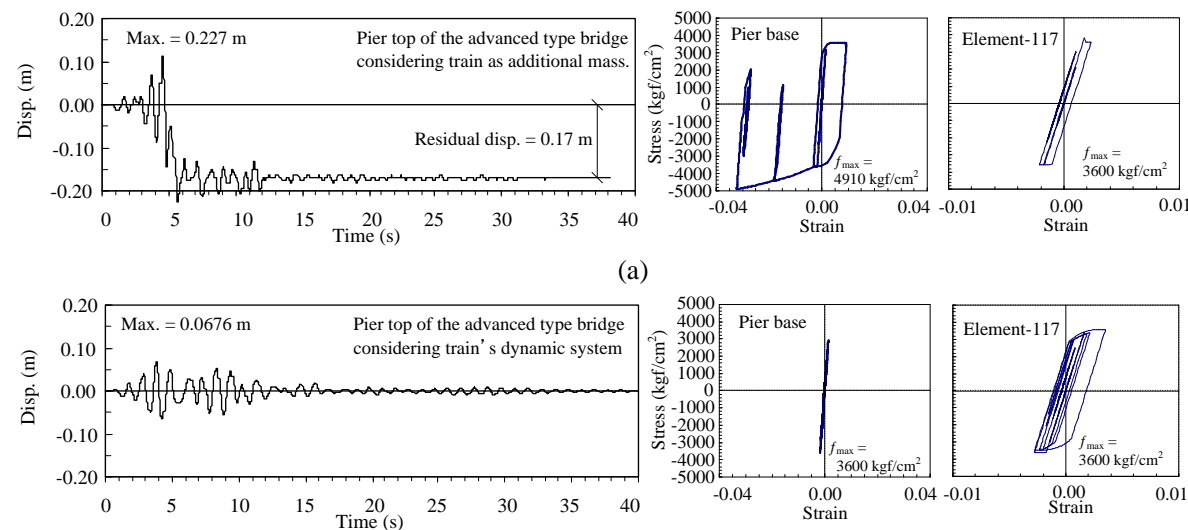

(b)

Fig. 9. Displacement responses at the pier top and stress-strain hysteresis loop at pier base of the advanced bridge subject to JR-Takatori-Station-EW (JRTS-EW) ground motion: (a) model considering train as additional mass; and (b) model considering train's dynamic system.
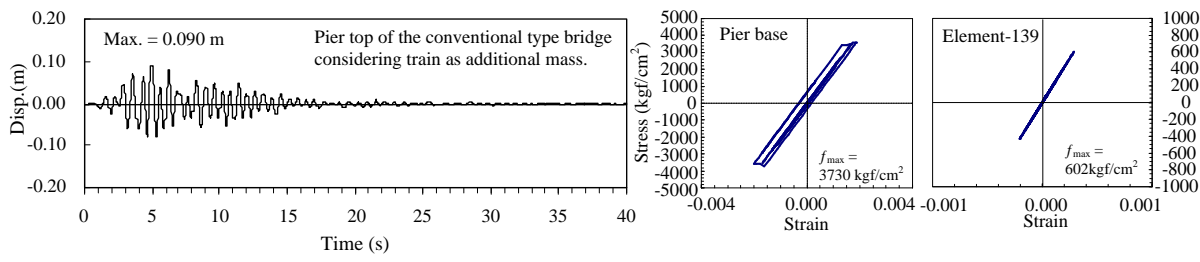

(a)
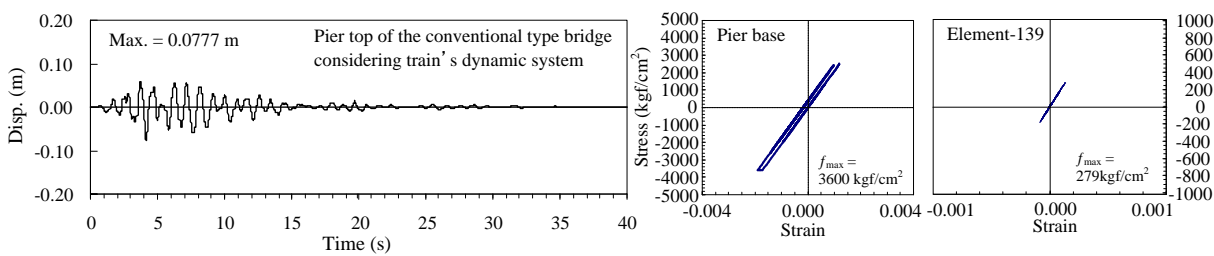

(b)

Fig. 10. Displacement responses at the pier top and stress-strain hysteresis loop at pier base of the conventional bridge subject to JR-Takatori-Station-EW (JRTS-EW) ground motion: (a) model considering train as additional mass; and (b) Model considering train's dynamic system. 

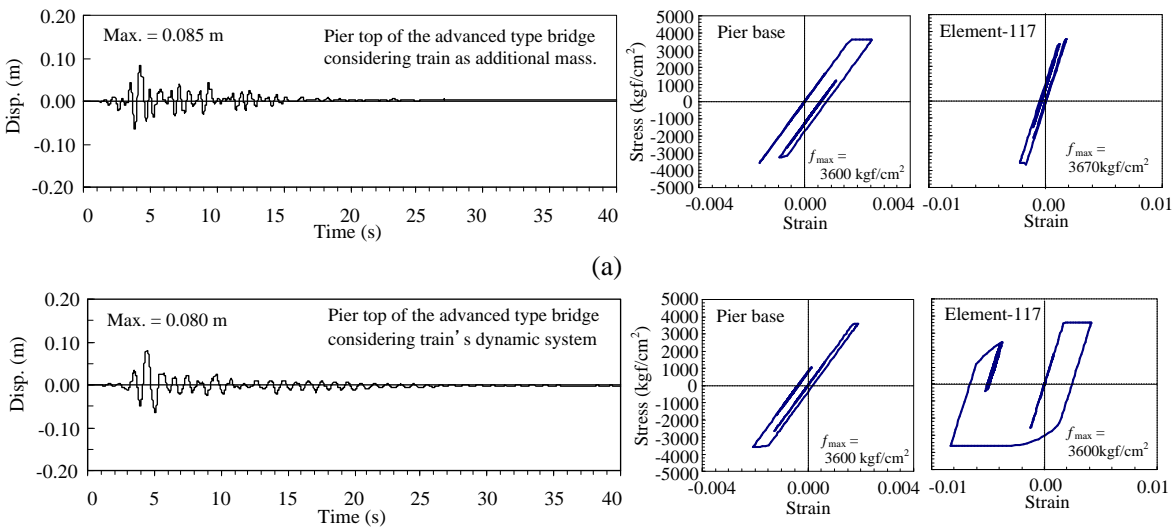

(b)

Fig. 11. Displacement responses at the pier top and stress-strain hysteresis loop at pier base of the advanced bridge subject to Osaka-Gas-Fukiai-EW (OSGF-EW) ground motion: (a) model considering train as additional mass; and (b) model considering train's dynamic system.
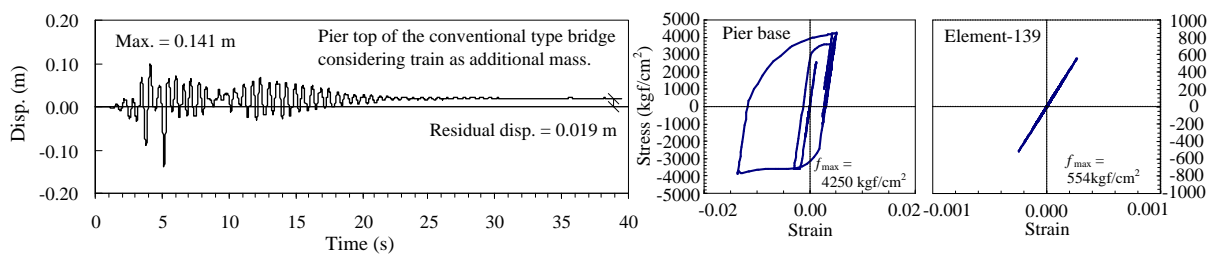

(a)
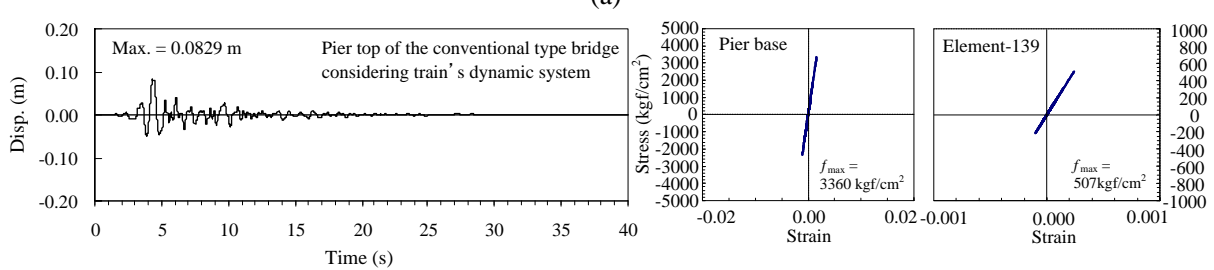

(b)

Fig. 12. Displacement responses at the pier top and stress-strain hysteresis loop at pier base of the conventional bridge subject to Osaka-Gas-Fukiai-EW (OSGF-EW) ground motion: (a) Model considering train as additional mass; and (b) Model considering train's dynamic system.

Table 3. Peak displacement and acceleration responses at pier top of bridges.

\begin{tabular}{cccccc}
\hline \multirow{2}{*}{ Ground motion } & Train model & \multicolumn{2}{c}{ Advanced bridge } & \multicolumn{2}{c}{ Conventional bridge } \\
& & Displ. (m) & Acc. (gal) & Displ. (m) & Acc. (gal) \\
\hline \multirow{2}{*}{ JRTS-NS } & Train as additional mass & 0.0800 & 566 & 0.0875 & 820 \\
& Train as dynamic system & 0.0728 & 425 & 0.0761 & 561 \\
\multirow{2}{*}{ JRTS-EW } & Train as additional mass & 0.2270 & 1160 & 0.0870 & 869 \\
& Train as dynamic system & 0.0676 & 419 & 0.0777 & 627 \\
& Train as additional mass & 0.0850 & 487 & 0.1410 & 1580 \\
& Train as dynamic system & 0.0800 & 420 & 0.0829 & 596 \\
\hline
\end{tabular}


Seismic responses under the OSGF-EW ground motion are shown in Figs. 11 and 12. The largest residual displacement of $1.9 \mathrm{~cm}$ at the pier top was observed at the conventional bridge considering the train as additional mass as shown in Fig. 12(a). The residual displacement was also caused by the plastic deformation at the pier base. For the conventional bridge, considering train as additional mass resulted in the most critical result. On the other hand, no clear residual displacement was observed in the advanced bridge differently from the result under the JRTS-EW ground motions shown in Fig. 9(a). This result supported the fact that JRA code recommend to consider at least three strong earthquakes to assess seismic performance of bridges.

An interesting point is that energy absorption by earlier plastic deformations of lateral bracing members than the pier base could save the pier base from a plastic deformation. For example earlier plastic deformation at the lateral bracing members (Element-117 of the advanced type bridge; and Elelment-139 of the conventional type bridge) of the bridges led to small residual displacements at the pier top as shown in Figs. 9(b) and 11(b). A contrary result was observed as shown in Figs. 9(a) and 12(a), in which plastic deformations were observed at the pier base while the lateral bracing members (Element-117 of the advanced type bridge; and Elelment-139 of the conventional type bridge) kept elastic behavior.

The numerical results demonstrated that the seismic responses of the pier base of the bridge model considering dynamic system of train were weaker than those responses of the model with considering train as additional mass. One reason of the phenomena might be the phase caused by difference of the dynamic characteristic of the monorail train and bridge system which could reduce inertia effects of the bridge system during the earthquakes. Peak displacement and acceleration responses at the pier top are summarized in Table 3.

Judging from the allowable residual-displacement tolerance shown in Eq. (4-1) which is specified in the JRA code [Japan Road Association, 2002], the average residual displacements of $5.7 \mathrm{~cm}$ and $0.63 \mathrm{~cm}$ respectively for the advanced and conventional type bridges satisfied the tolerance value of about $10 \mathrm{~cm}$. It was observed that the advanced bridge would satisfy the seismic performance even though the advanced bridge experienced the largest plastic deformation at the pier base.

$$
\delta_{R} \leq \delta_{R a}(=H / 100)
$$

where, $\delta_{R}$ is the average residual displacement; $\delta_{R a}$ indicates the allowable residual displacement; $H$ is the distance in meter between the pier base and the neutral axis of the girder.

The shear force at the bearings of the bridges (Node-208 of the advanced bridge; and Node-187 of the conventional type bridge) due to the JRTS-EW ground motion is summarized in Fig. 13. It was observed that the shear force at the bearing of the advanced bridge was greater than that of the conventional bridge, since the inertia effect of the advanced bridge was greater than that of the conventional bridge because of adopting heavier trackgirders. It also demonstrated that considering train as a dynamic system resulted in decrease of the shear force in comparison with that of the model considering train as additional mass. Other ground motions provided similar tendencies with JRTS-EW ground motion, and thus omitted. 

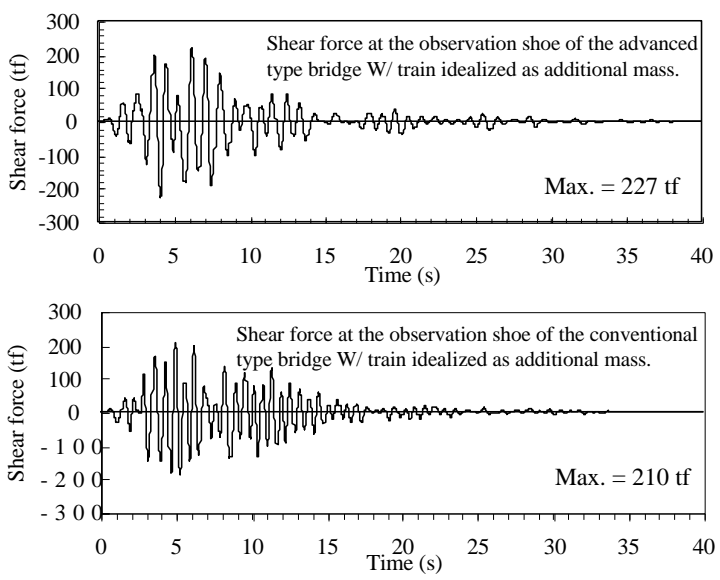

(a)
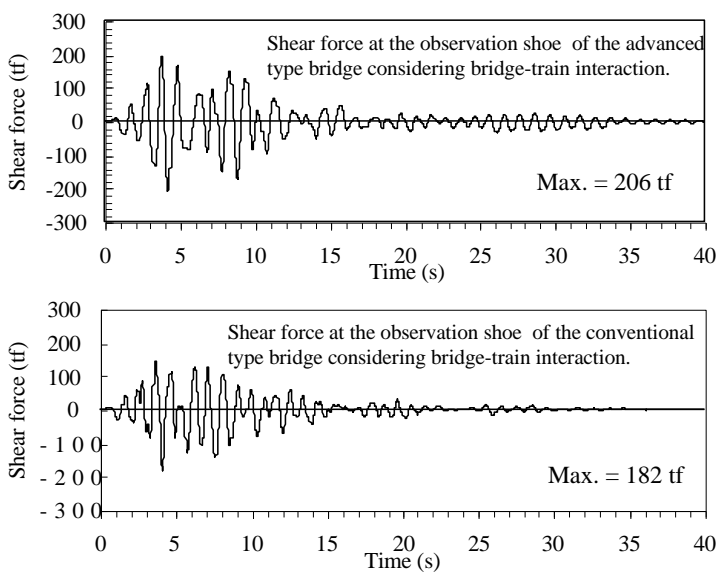

(b)

Fig. 13. Shear forces at the bearing subject to JR-Takatori-Station-EW (JRTS-EW) ground motions: (a) model considering train as additional mass; and (b) model considering train's dynamic system.

\section{Conclusions}

The seismic responses of the conventional and advanced monorail bridges were examined to investigate the effect of train's dynamic system on seismic performance of monorail bridges by means of a dynamic elasto-plastic response analysis.

Observations demonstrated that occurrence of the plastic deformations at the pier base of the steel monorail bridge depends on ground motions. Earlier plastic deformation at the lateral bracing members of the girder system absorbed seismic energy and reduced the stress at the pier base. The simplified structural details with heavier track girders of the advanced bridge were thought as a weak point in terms of seismic performance. However the earlier plastic deformation of secondary members would absorb seismic energy and could save damage at the pier base. 
All the considering bridges showed good seismic performance. In other words, it demonstrated that even the advanced bridge would satisfy the seismic performance despite the fact that the maximum residual displacement occurred in the advanced bridge. The shear force at the bearings of the advanced bridge was greater than that of the conventional bridge because of the increased inertia effect of the advanced bridge due to greater dead load comparing with that of the conventional type bridge. Observations through the analytical study showed that considering the monorail train as additional mass in numerical modeling overestimated the train load on seismic performance of monorail bridges.

\section{Acknowledgements}

The authors wish to express their gratitude for the financial support received towards this investigation from the Japanese Society for the Promotion of Science for the Grant-in-Aid for Scientific Research (B) under project no. 24360180.

\section{References}

Crisfield, M.A. [1979] "Faster modified Newton-Raphson iteration," Comp. Method in Applied Mech. Eng. 20, 269-278.

He, X., Kawatani, M., Hayashikawa, T. and Matsumoto, T. [2011] "Numerical analysis on seismic response of Shinkansen bridge-train interaction system under moderate earthquakes," Earthquake Eng. Eng. Vib. 10(1), 85-97.

Japan Road Association [2002] Japanese Specifications for Highway Bridges, Part V, Seismic Design.

Kameda, H., Murono, Y., Nanjou, A. and Sasaki, N. [1999] "Earthquake response of highway bridges under bridge-vehicle system," JSCE, J. of Struct. Mech. Earthquake Eng. 626(I-48), 93-106. (in Japanese)

Kawatani, M., Kim, C.W., Iwashita, K. and Yasui, K. [2008] "Seismic responses of highway viaducts incorporating bridge-vehicle interaction," J of JSCE, Division A: Struct. Eng./Earthquake Eng. Applied Mech. 64(4), 678-691. (in Japanese)

Kim, C.W. and Kawatani, M. [2006] "Effect of train dynamics on seismic response of steel monorail bridges under moderate ground motion," Earthquake Eng. Struct. Dyn. 35(10), 1225-1245.

Kim, C.W., Kawatani, M., Lee, C.H. and Nishimura, N. [2007] "Seismic response of a monorail bridge incorporating train-bridge interaction," Struct. Eng. Mech. 6(2), 111126.

Kim, C.W., Kawatani, M., Konaka, S. and Kitaura, R. [2011] "Seismic responses of a highway viaduct considering vehicles of design live load as dynamic system during moderate earthquakes," Struct. Infrastructure Eng. 7(7-8), 523-534.

Lee, C.H., Kawatani, M., Kim, C.W., Nishimura, N. and Kobayashi, Y. [2006] "Dynamic response of a monorail under a moving train," J. of Sound Vib. 294(3), 562-579.

Maruyama, Y. and Yamazaki, F. [2002] "Seismic response analysis on the stability of running vehicles," Earthquake Eng. Struct. Dyn. 31, 1915-1932.

Miyamoto, T., Ishida, H. and Matsuo, M. [1997] "Running safety of railway vehicle as earthquake occurs," $Q R$ of RTRI 38(3): 117-122.

Nishimura, N., Ono, K. and Ikeuchi, T. [1995] "The constitutive law of the steel materials 
which receive the repeated plastic history based on monotonic loading curve," JSCE, $J$. of Struct. Mech. Earthquake Eng. 513(I), 27-38. (in Japanese)

Nishimura, N., Ikeuchi, T. and Taniguchi, N. [1998] "Numerical simulation on damage to pipe piers in Hyogoken-Nanbu earthquake," Eng. Struct. 20, 291-299.

Ohnomi, T. [1996] "Seismic response characteristics of steel high pier bridge," Master thesis, Dept. of Civil Engineering, Osaka University, Osaka, Japan. (in Japanese)

Yang. Y.B. and Wu, Y.S. [2002] "Dynamic stability of trains moving over bridges shaken by earthquakes," J. Sound Vib. 258, 65-94. 